\title{
An evaluation of a logbook for trainees in accident \& emergency medicine in the United Kingdom: senior consultant opinion
}

\author{
C. LUKE, E. KADZOMBE, D. GORMAN and \\ A. ARMSTRONG \\ Merseyside Group of Senior Registrars in Accident \& Emergency Medicine
}

\section{SUMMARY}

A previous paper from the Merseyside Group of Senior Registrars in Accident \& Emergency Medicine examined the desirability of a logbook for Higher Specialist Training (HST) in accident \& emergency medicine in the United Kingdom and its principal ingredients (Luke et al., 1991). A survey of 100 senior registrars and recently appointed consultants in the specialty identified the main issues of importance to the majority of respondents e.g. certification in advanced cardiac and trauma life support, a minimum of three years in the speciality before appointment as senior registrar and certain key secondments.

In this paper, more senior consultants in the specialty were surveyed and a resounding majority concurred with the preferences of their junior colleagues. The findings are discussed and the implications for a future curriculum for postgraduate training in A\&E medicine are explored.

\section{INTRODUCTION}

The past decade has seen a surge of papers in the global medical literature that have examined the defects and desiderata of emergency medicine curricula for medical students and graduates. Among over 50 such articles (which have been published in the past few years), topics have ranged from contemplation by the Japanese of the value of their emergency departments in undergraduate education (Kawashima, 1989) to the development of academic departments of emergency medicine within American medical schools (Ling, 1990). 
Table 1. Training targets with over $90 \%$ support among respondents*

ACLS and ATLS Certification
Simple fracture/dislocation reduction
Central venous cannulation
Slit lamp ocular examination
Training in management and budgeting
Disaster planning
Medicolegal tuition
Training in information technology
Secondments: Ambulance
Police
Fire Service
General Practice
Regional Poisons Centre
* A\&E consultants appointed within 3
years and senior registars

Following a similar vein of enquiry, our previous paper sought and found the most popular ingredients of a hypothetical postgraduate training logbook among junior consultants and senior registrars in U.K. accident \& emergency medicine (Table 1) (Luke et al., 1991). With the silhouette of a clinical curriculum perceptigles to most, and with career A\&E registrar schemes established in places, this followio up survey was undertaken to examine the broad view of senior consultants in UK speciality on the future shape of HST, beyond basic clinical considerations.

\section{METHODS}

A 12-point questionnaire was circulated to 190 consultants in Accident \& Emergenc Medicine, in the U.K. and Ireland, who had been more than 4 years in posto The list of consultants was drawn mainly from the latest yearbook of the Britis Association for Accident \& Emergency Medicine (formerly the CSA) and was based on the Merseyside's Group's most recent collective knowledge. It was not exhaustive but was, we believe, reasonably representative of the senior consultan body.

The consultants were asked to record their approval for hypothetical targets within HST for A\&E Medicine by circling 'Yes' or ' $\mathrm{No}^{\prime}$ ' after the question 'woul you support these targets in a hypothetical logbook?' and were invited to submin their comments about the targets and HST in general. The dozen ingredients putw to the consultants were culled from the previous survey and were primarily non? clinical and 'over and above' conventional hospital-based training. They included the need for Advanced Training in Cardiac and Trauma Life Support (the intros duction of which has been perhaps the most visible change in British A\&E medicine during the past decade), the acquisition of skills in information technology, clinicas budgeting and management, secondments (e.g. to Regional Poisons Units, Genero 
Practice and the Emergency Services) which have been fasionable in the past few years and, centrally, the issue of whether a logbook is appropriate or desirable in A\&E medicine. No attempt was made to justify this eclectic menu other than by reference to the previous survey.

\section{RESULTS}

Of the 190 Senior Consultants who were circulated with our questionnaire, 127 (or $66.8 \%$ ) responded. This is an acceptable level of replies for a postal survey. The respondents' views were strictly categorized into affirmative ('yes'), negative ('no') and, where there was any doubt or equivocation in their answer, 'uncertain'. The relative support for the 12 items posited is illustrated in Fig. 1. In the section of the questionnaire set aside for the respondents' additional comments and suggestions the commonest recommendations were for adequate paediatric clinical training, education in 'proper' research methodology (beyond audit and surveys!), exchange posting to Emergency Medicine posts abroad and a casebook similar to that employed in obstetric training in the U.K. (in which real cases dealt with by the trainee are described with appropriate literature review in a thesis style). Only one respondent asked that the logbook be required at the interview for a consultant appointment but many were anxious that training be not overprescriptive.

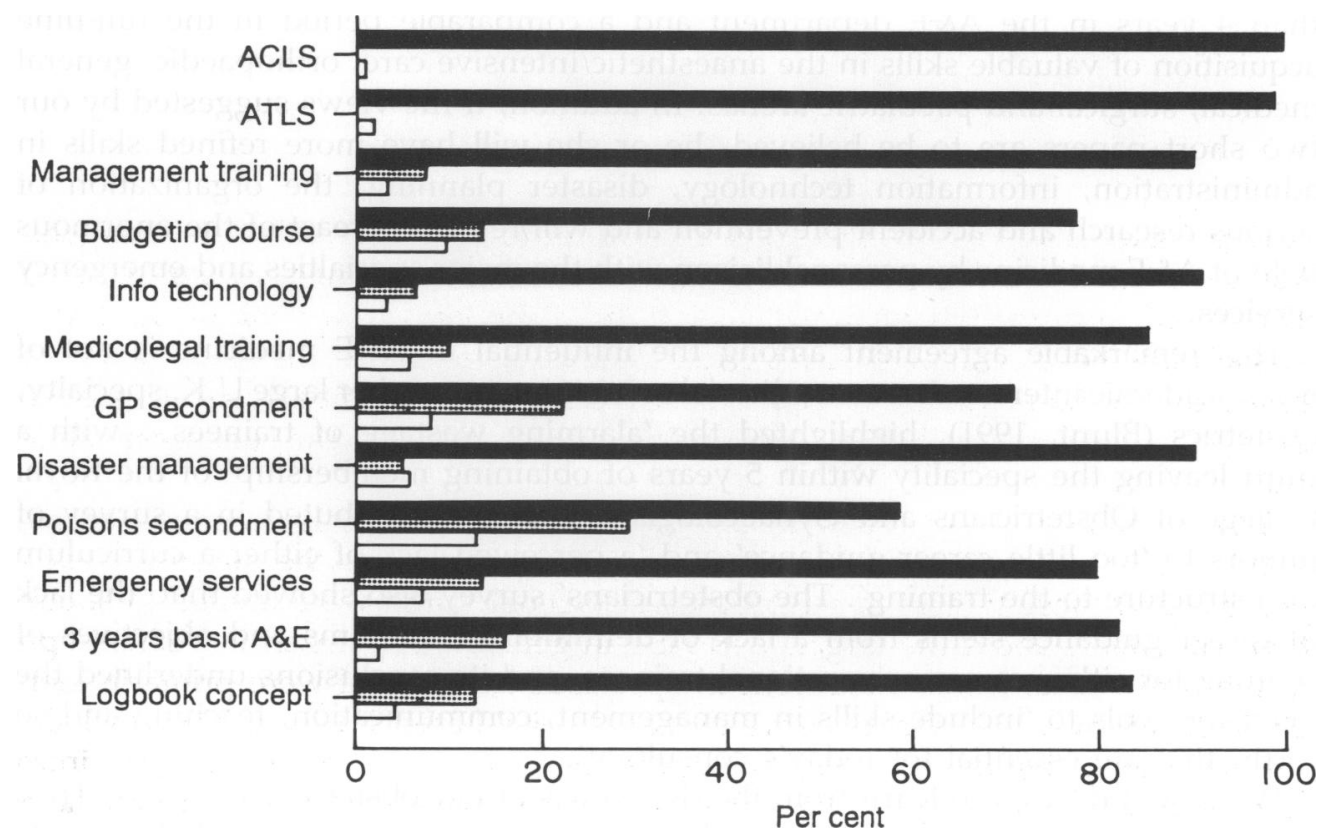

Fig. 1. Senior consultant support for training targets: $\bullet$, yes; 国, no; $\square$, uncertain. 
In the year since our last survey, fundamental changes in the nature of highe? specialist training (HST) in A\&E medicine have come about. New rules for $\overrightarrow{\sigma_{0}}$ 1990-1 issued by the Specialist Advisory Committee for A\&E Medicine (undero the auspices of the Joint Committee for Higher Medical Training at the Royat College of Physicians) entail the undertaking of HST from the time of appointment? as registrar in the speciality (JCHMT, 1990). After securing such a post, the individual is enrolled with the JCHMT, which oversees the entire training of thates person over a 5-year period. Training will now be a continuum, with an average $\overrightarrow{0}$ of 3 years spent as a registrar (including a year on attachment) and another $\vec{\omega}$ 2 years, ideally in another training programme, as a senior registrar. The new type of registrar will spend 2 years within one or more A\&E departments acquiring? appropriate clinical skills. This is to be complemented by a year or so, dedicated: to attachments of 3 months or more to germane specialities e.g. paediatrics, intensive care/anaesthesia or orthopaedics. Subsequently as senior registrars, $\omega$ they will develop or consolidate their administrative skills with a predominantly? A\&E-based training, but may be seconded briefly (mainly as observers) to special $-\vec{r}$ ities like plastic surgery, psychiatry or general practice, if lacking in previousw exposure.

The findings of this study, reassuringly, reveal widespread if indirect seniong consultant support for these recent changes in career structure, as well as a sig prising degree of consensus among all consultants and senior registrars in the speciality in relation to the future direction of HST. The next generation of cop-s sultants, it is to be hoped, will emerge from a training programme with not lesso than 4 years in the A\&E department and a comparable period in the full-time acquisition of valuable skills in the anaesthetic/intensive care, orthopaedic, genera? medical, surgical and paediatric arenas. In addition, if the views suggested by ourg two short papers are to be believed, he or she will have more refined skills in administration, information technology, disaster planning, the organization op serious research and accident prevention and will remain abreast of the enormous field of A\&E medicine by personal liaison with the major specialties and emergency. services.

This remarkable agreement among the influential in A\&E medicine is not of mere academic interest. A recent editorial on training in another large U.K. specialty, obstetrics (Blunt, 1991), highlighted the 'alarming wastage of trainees... with as third leaving the speciality within 5 years of obtaining membership' of the Royat College of Obstetricians and Gynaecologists. This was attributed in a survey of: juniors to 'too little career guidance' and 'a perceived lack of either a curriculumo or a structure to the training'. The obstetricians' survey also showed that 'the lackN of career guidance stems from a lack of definition of the aims and objectives of training for either career or vocational trainees, and its conclusions underlined the need for goals to 'include skills in management, communication, teaching and so: forth, that are essential for today's consultant'.

We would do well to learn from the difficulties of our obstetric colleagues. They have for years employed a training logbook yet (it now seems) have failed to clarify the necessary ingredients or objectives, with consequent serious disenchantmen $\frac{\mathbb{Q}}{\mathbb{Q}}$ 
among trainees. To add to this, privately expressed opinion among junior obstetricians is against their logbook: their experience concurs with the views of a vehement minority of the respondents to the A\&E survey and suggests that logbooks 'merely obfuscate and irritate'.

We can learn much too from our North American colleagues in emergency medicine who have had a College since 1968. Recently, there has been much analysis of their residency programs with respect to residents' satisfaction with training, realistic content and appeal to would-be applicants (Moorhead et al., 1989; Koscove, 1990). U.S. emergency medicine residents are, on the whole, reasonably satisfied with their training; nevertheless, improvements in their education are being sought constantly e.g. in the areas of communication and administration, in the use of computers to match residents' experience with their requirements, and in the coding of training programs to allow objective evaluation (Moorhead, 1989; Langdorf, 1990; Tintinalli, 1990).

Accident and emergency medicine in the UK is less well established than in the U.S.A. yet it is expanding rapidly and is attracting growing numbers of talented graduates. If this growth is to be sustained and the speciality enhanced, it is imperative to learn from the experiences of others and to clarify the goals of training; it is equally important to identify, for all to see, a comprehensive but fluid syllabus. The two surveys that we have carried out were prompted by our initial attraction to a logbook; indeed, we have shown it to be a remarkably popular vehicle in theory for a new curriculum. Our exploration nonetheless has shown that any experiment with logbooks should not impede the production of a curriculum founded on consensus, common sense and regular review.

\section{REFERENCES}

Blunt S. (1991) Training in obstetrics (Editorial). British Medical Journal 303, 1416

Joint Committee on Higher Medical Training. (1990) Training handbook 1990-1: Accident and Emergency Medicine, pp. 27-30.

Kawashima K. (1989) Key points in clinical training: the emergency department. Kurinikaru Sutndi 7 (4), 413-414.

Koscove E. M. (1990) An applicant's evaluation of an emergency medicine internship and residency. Annals of Entergency Medicine 19 (7), 774-780.

Langdorf M. I., Strange G., Macneil P. (1990) Computerized tracking of emergency medicine resident clinical experience. Annals of Emergency Medicine 19 (7), 764-777.

Ling L. J. (1990) Attaining academic department status for emergency medicine within medical schools. Annals of Emergency Medicine 19 (7), 793-796.

Luke C., Kadzombe E., Gorman D. \& Armstrong A. (1991) An evaluation of a logbook for trainees in accident and emergency medicine in the United Kingdom. Archives of Entergency Medicine 8, $130-134$.

Moorhead J. C., Adams B. E., Aghababian R. V., et al. (1989) An assessment of emergency medicine residency graduates' perceptions of the adequacy of their residency training. Annals of Emergency Medicine 18, 701-704.

Tintinalli J. E. (1990) The need for coding systems to evaluate emergency residency programs (Editorial). Annals of Emergency Medicine 19 (7), 827-828. 